\title{
Peroral endoscopic myotomy (POEM) vs pneumatic dilation (PD) in treatment of achalasia: A meta-analysis of studies with $\geq 12$-month follow-up
}

\section{다(1)우우}

\author{
Authors \\ Andrew Ofosu*, 1, Babu P. Mohan*,2, Yervant Ichkhanian³, Maen Masadeh', John Febin', Mohamed Barakat', Daryl \\ Ramai $^{1}$, Saurabh Chandan ${ }^{5}$, Gulara Haiyeva ${ }^{6}$, Shahab R. Khan ${ }^{7}$, Mohamad Aghaie Meybodi ${ }^{8}$, Antonio Facciorusso ${ }^{9}$, \\ Alessandro Repici ${ }^{10}$, Sachin Wani ${ }^{11}$, Nirav Thosani ${ }^{12}$, Mouen A. Khashab ${ }^{8}$
}

Institutions

1 Gastroenterology and Hepatology, Stanford University, Stanford, California, United States

2 Gastroenterology and Hepatology, University of Utah Health, Salt Lake City, Utah, United States

3 Internal Medicine, Henry Ford University Medical Center, Detroit, Michigan, United States

4 Kaiser Permanente Northern California, California, United States

5 Gastroenterology and Hepatology, University of Nebraska, United States

6 Beneficts Hospital Inc., Great Falls, Montana, United States

7 Gastroenterology, Rush University Medical Center, Chicago, Illinois, United States

8 Gastroenterology and Hepatology, John Hopkins University Hospital, Baltimore, Maryland, United States

9 Gastroenterology Unit, Department of Medical Sciences, University of Foggia, Foggia, Italy

10 Humanitas Research Hospital, Humanitas University, Rozzano, Milan, Italy

11 Gastroenterology, University of Colorado School of Medicine, Aurora, Colorado, United States

12 Gastroenterology, Hepatology and Nutrition, University of Texas Health Science Center at Houston, Houston, Texas, United States

submitted 22.7.2020

accepted after revision 23.11 .2020

Bibliography

Endosc Int Open 2021; 09: E1097-E1107

DOI 10.1055/a-1483-9406

ISSN 2364-3722

(c) 2021. The Author(s).

This is an open access article published by Thieme under the terms of the Creative Commons Attribution-NonDerivative-NonCommercial License, permitting copying and reproduction so long as the original work is given appropriate credit. Contents may not be used for commercial purposes, or adapted, remixed, transformed or built upon. (https://creativecommons.org/licenses/by-nc-nd/4.0/)
Georg Thieme Verlag KG, Rüdigerstraße 14, 70469 Stuttgart, Germany

Corresponding author

Mouen Khashab, MD, Associate Professor of Medicine,

Director of Therapeutic Endoscopy, Johns Hopkins Hospital, Sheikh Zayed Bldg, Division of Gastroenterology and Hepatology, 1800 Orleans Street, Suite 7125G, Baltimore, MD 21287, USA

Fax: +1-443-683-8335

mkhasha1@jhmi.edu

\# Supplementary material is available under https://doi.org/10.1055/a-1483-9406

\section{ABSTRACT}

Background and study aims Peroral endoscopic myotomy (POEM) is increasingly being used as the preferred treatment option for achalasia. The aim of this systematic review and meta-analysis was to compare the efficacy and safety of POEM versus pneumatic balloon dilation (PD).

Methods We performed a comprehensive review of studies that reported clinical outcomes of POEM and PD for the treatment of achalasia. Measured outcomes included clinical success (improvement of symptoms based on a validated scale including an Eckardt score $\leq 3$ ), adverse events, and post-treatment gastroesophageal reflux disease (GERD).

Results Sixty-six studies (6268 patients) were included in the final analysis, of which 29 studies (2919 patients) reported on POEM and 33 studies (3050 patients) reported on PD and 4 studies (299 patients) compared POEM versus PD. Clinical success with POEM was superior to PD at 12,24 , and 36 months ( $92.9 \%$, vs $76.9 \% P=0.001 ; 90.6 \%$ vs $74.8 \%$, $P=0.004 ; 88.4 \%$ vs $72.2 \%, P=0.006$, respectively). POEM was superior to PD in type I, II and III achalasia (92.7\% vs $61 \%, P=0.01 ; 92.3 \%$ vs $80.3 \%, P=0.01 ; 92.3 \%$ v $41.9 \%, P=$ 0.01 respectively)

\footnotetext{
* Drs. Ofosu and Mohan: These authors contributed equally.
} 
Pooled OR of clinical success at 12 and 24 months were significantly higher with POEM (8.97; $P=0.001$ \& 5.64; $P=0.006)$. Pooled OR of GERD was significantly higher with POEM (by symptoms: 2.95, $P=0.02$ and by endoscopic findings: $6.98, P=0.001)$. Rates of esophageal perforation $(0.3 \%$ vs $0.6 \%, P=0.8)$ and significant bleeding ( $0.4 \%$ vs $0.7 \%, P=$ 0.56 ) were comparable between POEM and PD groups.

Conclusions POEM is more efficacious than PD in the treatment of patients with achalasia during short-term and longterm follow-up, albeit with higher risk of abnormal esophageal acid exposure.

\section{Introduction}

Achalasia is a progressive esophageal motility disorder of unknown etiology. The disease pathology is characterized by the degeneration of inhibitor neurons that are involved in the phasic relaxation of the lower esophageal sphincter (LES) [1]. This results in loss of propulsive peristalsis and failure of LES relaxation. Clinical symptoms include dysphagia, chest pain, regurgitation and weight loss [2]. Approximately 1 in 100,000 of the population per year is affected by this disorder [3]. If left untreated, achalasia profoundly impairs a person's quality of life.

Treatment of achalasia is aimed at lowering the functional resistance of the LES to bolus progression. Options include pharmacological therapy, endoscopic botulinum toxin injection (EBTI), or disruption of the muscular bundles of LES by pneumatic balloon dilation (PD) or surgical myotomy of the LES [4]. Pneumatic dilation and laparoscopic Heller myotomy have been shown to be effective treatment options in the management of achalasia patients [5].

Recently, peroral endoscopic myotomy (POEM) is increasingly being used for the treatment of achalasia due to its minimally invasive nature [6,7]. Although the success and safety of POEM have been widely reported, the best endoscopic modality to treat achalasia with long-term results remains undecided. POEM and PD are both performed endoscopically, however, studies comparing the clinical outcomes and safety of POEM to PD are limited by few studies with small sample size. Multiple meta-analyses have been conducted to compare outcomes of different treatment modalities in achalasia but no studies have compared long-term outcomes of POEM and PD by meta-analysis, both of which are endoscopically performed and it is the most appropriate to compare these techniques unlike studies that have compared POEM to surgical methods. To this end, we conducted a meta-analysis to study and compare the clinical outcomes of POEM to PD in the treatment of achalasia.

\section{Methods}

\section{Search strategy}

We performed a comprehensive review of studies published until September 2019 that reported clinical outcomes of POEM and/or PD for the treatment of achalasia according to the Preferred Reporting Items for Systematic reviews and Meta-analysis (PRISMA) Epidemiology guidelines. Four databases were searched: PubMed, EMBASE, Ovid, and Cochrane. An experienced medical librarian using inputs from the study authors helped with the literature search. Keywords used were: "achala- sia," "myotomy," "Pneumatic dilation" "peroral endoscopic myotomy," and "POEM." The full search strategy is available in Appendix 1. The PRISMA and MOOSE checklist were followed and are provided as Appendixes 2 and $3[8,9]$.

\section{Study selection}

In this meta-analysis, we included studies that evaluated the clinical outcomes of POEM and studies that evaluated the outcomes of PD in patients with achalasia. Studies were included irrespective of inpatient/outpatient setting and geography as long as they provided data needed for the analysis.

Our exclusion criteria were as follows: (1) Conference abstracts, general reviews or commentaries; (2) studies with sample size <20; (3) studies with follow-up time < 12 months; (4) studies done in pediatric population (age <18 years); (5) studies not published in the English language; and (6) non-achalasia motility disorders. In case of multiple publications from the same cohort and/or overlapping cohorts, data from the most recent and/or most appropriate comprehensive report were retained.

\section{Data abstraction and quality assessment}

Data on study-related outcomes in the individual studies were abstracted onto a standardized form by at least four authors (AO, SR, BPM, SRK), and two authors (BPM, AO) did the quality scoring independently. Primary study authors were contacted via email when needed for further information and/or clarification on data was required. The Cochrane tool for assessing risk of bias was used for Randomized Clinical trial and the Newcastle-Ottawa scale (NOS) for nonrandomized studies. The NOS assesses studies regarding the following 3 aspects: selection, comparability, and exposure. The score range of NOS is from 0 to $8[10]$.

\section{Outcomes assessed}

Clinical success was defined by improvement of symptoms based on a validated score, including Eckardt score $\leq 3$, improvement in dysphagia score (Watson dysphagia score, Vantrappen and Hellemans score): by pooled odds ratio (OR) POEM vs PD \& by subgroup comparison of pooled rates at 12 months, 24 months and 36 months from cohort studies.

Pooled clinical success of POEM versus PD was defined according to manometric achalasia subtype based on comparison of pooled rates from cohort studies.

GERD (classified by symptoms, endoscopic findings \& 24$\mathrm{pH}$ measurement) was defined by pooled odds ratio (POEM vs 
PD) \& by subgroup comparison of pooled rates from cohort studies.

Procedure-related adverse events (AE) assessed included mucosal injury/perforation, major bleeding, subcutaneous emphysema, pneumothorax, pneumoperitoneum, pneumonia, post- POEM and PD. All AEs were graded based on the American Society of Gastrointestinal Endoscopy Lexicon classification systems and categorized based on the severity of complication which as defined by the ASGE lexicon) [11].

\section{Assessment methodology and definitions}

Comparison analysis was performed by two methods, which were as follows:

(1) Pooled odds ratio (OR) for clinical success was calculated from studies that compared POEM and PD; and (2) subgroup comparison analysis between the pooled clinical success rate with POEM and with PD. The subgroup model of indirect comparison is comparable to a retrospective case-control study and is considered non-causal, as many inherent biases between the groups may remain uncontrolled [12].

\section{Statistical analysis}

We used meta-analysis techniques to calculate the pooled estimates in each case following the methods suggested by DerSimonian and Laird using the random-effects model [13]. When the incidence of an outcome was zero in a study, a continuity correction of 0.5 was added to the number of incident cases before statistical analysis [14].

We assessed heterogeneity between study-specific estimates by using Cochran $Q$ statistical test for heterogeneity, $95 \%$ prediction interval $(\mathrm{PI})$, which deals with the dispersion of the effects [15-17], and the $I^{2}$ statistics $[18,19]$. In this, values $<30 \%, 30 \%$ to $60 \%, 61 \%$ to $75 \%$, and $>75 \%$ were suggestive of low, moderate, substantial, and considerable heterogeneity, respectively [20].

Publication bias was ascertained, qualitatively, by visual inspection of funnel plot and quantitatively, by the Egger test [21]. When publication bias was present, further statistics using the fail-Safe $\mathrm{N}$ test and Duval and Tweedie's "Trim and Fill" test was used to ascertain the impact of the bias [22]. Three levels of impact were reported based on the concordance between the reported results and the actual estimate if there were no bias. The impact was reported as minimal if both versions were estimated to be same, modest if effect size changed substantially but the final finding would still remain the same, and severe if basic final conclusion of the analysis is threatened by the bias [23].

Comparison between the two treatments was performed by means of subgroup comparison on the meta-analysis software. The comparison is based on two-sided (bivariate) testing and $P$ $<0.05$ to define significance between the groups compared.

All analyses were performed using Comprehensive Meta-Analysis (CMA) software,version 3 (BioStat, Englewood, New Jersey, United States).

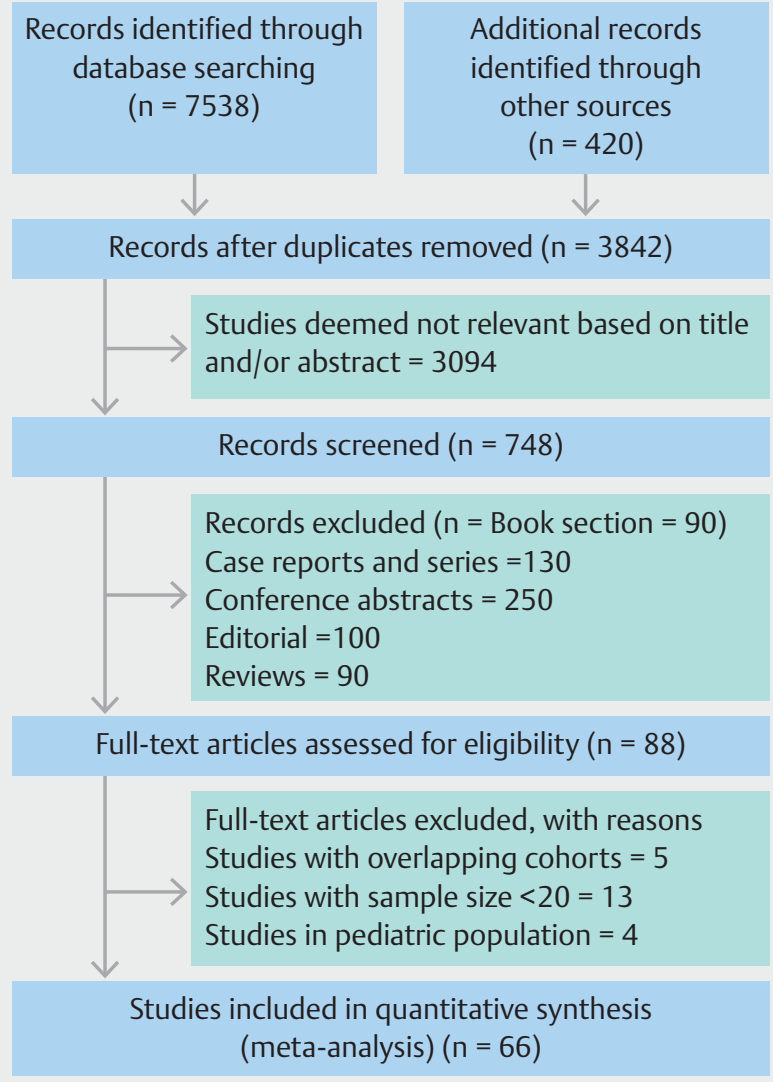

- Fig. 1 Study selection flowchart.

\section{Results}

\section{Search results and population characteristics}

From an initial 3842 studies, 3094 studies were deemed not relevant based on the title and/ or abstract. 748 records were screened, and 88 full-length articles were assessed. Sixty-six studies[24-89] were included in the final analysis, four of which directly compared outcomes of POEM to PD [32, 35, 36, 38]. A total of 29 studies reported on the outcomes of POEM [24-31, $33,34,37,39-45,51,63,65,73,77-80,83,85,87]$ and 33 reported on the outcomes of PD [46-50,52-62, 64, 66-72, 74$76,81,82,84,86,88,89]$. The schematic diagram of study selection is illustrated in $\mathbf{F i g . 1}$. These studies were published between Jan 2000 and July 2019. A total of seven studies were multicenter $[35,40,68,78,79,83,89]$. Of the 66 included studies, 62 were cohort studies (30 retrospective and 32 prospective), three case series and one randomized controlled trial.

Mean patients' age across studies was similar between the two procedures (POEM 47.0 vs. PD $45.1 \mathrm{yr}, P=0.63$ ). The proportion of males was also similar between both groups (51 vs. $55 \%, P=0.09)$. The mean duration of follow-up was similar between POEM versus PD (41.5 vs. 46.2 mo, $P=0.80$ ). The proportion of patients with type 1 achalasia (28.7\% versus $28.5 \%$, $P=0.93$ ) and type II achalasia (58.3\% versus $61.5 \%, P=0.17$ ) achalasia were similar between the two procedures. The pro- 
portion of patients with type III achalasia, were significantly higher in patients who had POEM versus PD (13\% vs $10 \%, P=$ $0.04)$. The population characteristics are described in Supplementary Table 1, Supplementary Table 2, Supplementary Table 3.

\section{Quality of included studies}

The detailed assessment of study quality can be found in Supplementary Table4. Overall, three studies [32,36,38] were considered high quality and the rest $[12,24-34,36-42,44$, 46-56, 58-91] were considered of medium quality. There were no low-quality studies.

\section{Meta-analysis outcomes}

A total of 6268 patients were included in the analysis from 66 studies. In the 4 studies that compared POEM to PD [32,35, 36,38], 142 patients were treated by POEM and 157 patients were treated by PD. Whereas in the cohort studies, 29 studies including 2919 patients reported on POEM [24-28, 30, 31, 33, $34,37,39-45,51,63,65,73,77-80,85,87,92]$, and 33 studies including 3050 patients reported on PD [46, 48-50, 52-62, 64, $66-72,74-76,81,82,84,86,88,89]$.

On analysis of the four studies that compared POEM versus PD in the treatment of achalasia, technical success was similar between both groups ( $100 \%$ versus $100 \%, P=0.82$ ). The pooled OR of clinical success of POEM (143 patients) versus PD (154 patients) at 12-months was $8.97(95 \% \mathrm{Cl} 3.85-20.86, P=$ 0.001) (Supplementary Fig.1) ( $\triangleright$ Table 1) and the pooled OR of clinical success of POEM (105 patients) versus PD (110 patients) at 24-months was $5.64(95 \% \mathrm{Cl} 1.65-19.24, P=0.006)$ ( $\triangleright$ Table 1) (Supplementary Fig. 2). The pooled proportion of clinical success with POEM at 12 months was $95.6 \%$ (95\% 89.7-98.1) and with PD was 66.7\% (95\% Cl 57.8-74.5). The pooled proportion of 24 -months clinical success with POEM was $92.3 \%(95 \% \mathrm{Cl} 85.4-96.1)$ and with PD was $67.1 \%(95 \% \mathrm{Cl}$ 45.9-83).

\section{Cohort studies}

The technical success was similar between both groups POEM vs PD (97\% versus $98 \%, P=0.62)$. Based on meta-analysis of non-comparative studies, the pooled 12-months clinical success rate with POEM (929) patients was 92.9\% (95\% Cl 89.495.3) and with PD (718 patients) was $76.9 \%$ (95\% Cl 71.181.8) ( Fig. 2). The pooled 24-months clinical success rate with POEM (523 patients) was $90.6 \%$ (95\% Cl 84.1-94.6) and with PD (478 patients) was $74.8 \%$ (95\% Cl 63.9-83.3) (• Fig. 3 ). The pooled 36-months clinical success rate with POEM (289 patients) was $88.4 \%(95 \% \mathrm{Cl} 80.5-93.3)$ and with PD (120 patients) was $72.2 \%$ (95\% Cl 62.2-80.4) ( Fig.4). Based on the non-causal subgroup comparison, the pooled clinical success rates with POEM at 12-months, 24-months and 36-months were significantly superior when compared to the respective pooled clinical success rates with PD $(P=0.001,0.004$, and 0.006 , respectively) ( $\triangleright$ Table 1$)$. Mean procedural time (min) and mean length of stay (days) were longer in the POEM group vs PD group (92 vs 26.5 minutes, $P<0.0001$ ) and (3.4 vs 1.9 days, $P=0.03)$, respectively. The length of stay after POEM pro- cedure in the United States was 1 to 3 days and in centers from Asia/Europe was 3 to 8 days.

\section{Achalasia subtype analysis}

When analyzed according to achalasia subtype, pooled success rates for POEM were superior to PD in type I (92.7\%, 83.3.-97\% vs $61 \%, 48.4-72, P=0.01$ ) (Supplementary Fig.3), type II (96.6\%, 89.3-99 vs 80.3\%, 62.4-90.9, $P=0.01$ ) (Supplementary Fig.4) and type III (92.3\%, 85.8-95.9 vs $41.9 \%, 27.0-$ 58.5, $P=0.01$ ) (Supplementary Fig.5) based on non-casual subgroup analysis.

Post- procedure reflux symptoms and reflux esophagitis Comparative studies: The pooled OR of GERD by symptoms for POEM (137patients) versus PD (124 patients) was 2.95 (95\% Cl 1.46-5.95, $P=0.02$ ) (Supplementary Fig. 6) and the pooled OR of GERD by EGD finding of esophagitis POEM (105 patients) versus PD (100 patients) was 6.98 (95\% Cl 2.41-20.22, $P=0.001)$ (Supplementary Fig.7) on analysis of the four studies that compared POEM to PD in the treatment of achalasia.

Cohort studies: Based on meta-analysis of 28 cohort studies, the pooled rate of GERD by symptoms (POEM 941 patients vs PD 729 patients) was $19 \%(13.7-25.8)$ vs $17.8 \%(12.7-24.4) P$ $=0.78$ (Supplementary Fig. 8); by reflux esophagitis (POEM 856 patients vs PD 437 patients) was $27.5 \%$ (17.5-40.3) vs 14.1\% (5.7-30.8), $P=0.15$ Supplementary Fig.9); and by $\mathrm{pH}$ measurement (POEM 196 patients vs PD 166 patients) was $48.6 \%$ (31.6-66) vs $41.3 \%$ (22.8-62.6) $P=0.61$, (Supplementary Fig. 10) ( Table 1).

\section{Adverse events}

Overall pooled adverse events (AEs) with POEM versus PD were comparable; mucosal injury POEM vs PD (4.5\% vs $3.9 \%, P=$ $0.60)$, esophageal perforation POEM vs PD $(0.3 \%$ vs $0.6 \%, P=$ $0.80)$, significant bleeding POEM vs PD $(0.4 \%$, vs $0.7, P=0.56)$, subcutaneous emphysema POEM vs PD (6.5\% vs $5.8 \%)$, pneumothorax POEM vs PD (1.4\% vs $1.7, P=065)$ and pneumomediastinum POEM vs PD ( $1.8 \%$ versus $1.5 \%, P=054)$.

Based on the ASGE lexicon for AEs, mild AEs POEM vs PD $(2.8$ $\%$ vs $2 \%, P=0.5)$ (Supplementary Fig. 11), moderate AEs POEM vs PD (3.1\% vs $2.3 \%, P=0.10)$ (Supplementary Fig. 12), and severe AEs POEM vs PD (1.4\% vs $1.8 \%$ ) (Supplementary Fig. 13), were comparable. There was no procedure-related mortality with either procedure.

\section{Validation of meta-analysis results}

Sensitivity analysis

To assess whether any one study had a dominant effect on the meta-analysis, we excluded one study at a time and analyzed its effect on the main summary estimate. In this analysis, no single study significantly affected the outcome or the heterogeneity (Supplementary Fig. 14, 15, and 16). 
Table 1 Summary of results

\begin{tabular}{|c|c|c|c|}
\hline Outcomes & \multicolumn{3}{|c|}{$\begin{array}{l}\text { Odds ratio } \\
\text { ( } 4 \text { studies, POEM: } 142 \text { patients, PD: } 157 \text { patients, } I^{2} \text { ) }\end{array}$} \\
\hline Clinical success at 3 months ( 4 studies) & \multicolumn{3}{|c|}{$6.67(2.15-20.69), P=0.001,1^{2}=0$} \\
\hline Clinical success at 12 months ( 4 studies) & \multicolumn{3}{|c|}{$8.97(3.85-20.86), P=0.001, I^{2}=0$} \\
\hline Clinical success at 24 months ( 3 studies) & \multicolumn{3}{|c|}{$5.64(1.65-19.24), P=0.006, I^{2}=38$} \\
\hline GERD by symptoms (4 studies) & \multicolumn{3}{|c|}{$2.95(1.46-5.95), P=0.02, I^{2}=0$} \\
\hline \multirow[t]{2}{*}{ GERD by EGD (3 studies) } & \multicolumn{3}{|c|}{$6.98(2.41-20.22), P=0.001, I^{2}=0$} \\
\hline & $\begin{array}{l}\text { POEM } \\
\text { (26 studies, } 2703 \text { patients) }\end{array}$ & $\begin{array}{l}\text { PD } \\
\text { (30 studies, } 2618 \text { patients) }\end{array}$ & $P$ value (2-sided comparison) \\
\hline \multicolumn{4}{|l|}{ Clinical success } \\
\hline 12-months & $\begin{array}{l}92.9 \%(89.4-95.3,26) \\
10 \text { studies } \\
\text { (PI: } 85 \text { to } 97)\end{array}$ & $\begin{array}{l}76.9 \%(71.1-81.8,70) \\
14 \text { studies } \\
\text { (PI: } 52 \text { to } 91)\end{array}$ & 0.001 \\
\hline 24-months & $\begin{array}{l}90.6 \%(84.1-94.6,59) \\
8 \text { studies } \\
\text { (PI: } 71 \text { to } 97)\end{array}$ & $\begin{array}{l}74.8 \%(63.9-83.3,86) \\
10 \text { studies } \\
\text { (PI: } 27 \text { to } 96)\end{array}$ & 0.004 \\
\hline 36-months & $\begin{array}{l}88.4 \%(80.5-93.3,0) \\
4 \text { studies } \\
\text { (PI: } 67 \text { to 97) }\end{array}$ & $\begin{array}{l}72.2 \%(62.2-80.4,74) \\
5 \text { studies } \\
\text { (PI: } 29 \text { to } 94)\end{array}$ & 0.006 \\
\hline \multicolumn{4}{|l|}{ GERD } \\
\hline Symptoms & $\begin{array}{l}19 \%(13.7-25.8,75) \\
13 \text { studies } \\
\text { (PI: } 7 \text { to } 42)\end{array}$ & $\begin{array}{l}17.8 \%(12.7-24.4,85) \\
13 \text { studies } \\
(\mathrm{PI}: 4 \text { to } 53)\end{array}$ & 0.78 \\
\hline EGD & $\begin{array}{l}27.5 \%(17.5-40.3,95) \\
17 \text { studies } \\
\text { (PI: } 3 \text { to } 83)\end{array}$ & $\begin{array}{l}14.1 \%(5.7-30.8,89) \\
6 \text { studies } \\
(1 \text { to } 85)\end{array}$ & 0.15 \\
\hline $\mathrm{pH}$ & $\begin{array}{l}48.6 \%(31.6-66,30) \\
6 \text { studies } \\
\text { (PI: } 19 \text { to } 79)\end{array}$ & $\begin{array}{l}41.3 \%(22.8-62.6,90) \\
3 \text { studies } \\
\text { (PI: } 0 \text { to } 100)\end{array}$ & 0.61 \\
\hline \multicolumn{4}{|l|}{ Adverse events } \\
\hline Mild & $\begin{array}{l}2.8 \%(1.6-4.9,47) \\
19 \text { studies } \\
\text { (PI: } 1 \text { to } 23)\end{array}$ & $\begin{array}{l}2 \%(1-4.2,0) \\
13 \text { studies } \\
\text { (PI: } 1 \text { to } 4)\end{array}$ & 0.5 \\
\hline Moderate & $\begin{array}{l}3.1 \%(1.9-5.1,57) \\
19 \text { studies } \\
\text { (PI: } 1 \text { to } 22)\end{array}$ & $\begin{array}{l}2.3 \%(0.6-3.4,0) \\
13 \text { studies } \\
\text { (PI: } 1 \text { to } 4)\end{array}$ & 0.1 \\
\hline Severe & $\begin{array}{l}1.4 \%(0.7-2.5,0) \\
19 \text { studies } \\
\text { (PI: } 1 \text { to } 3 \text { ) }\end{array}$ & $\begin{array}{l}1.8 \%(0.9-3.5,0) \\
13 \text { studies } \\
\text { (PI: } 1 \text { to } 4)\end{array}$ & 0.5 \\
\hline Egger's publication bias ( $P$ value) & \multicolumn{3}{|l|}{ 2-tailed: 0.15} \\
\hline
\end{tabular}

\section{Heterogeneity}

We assessed dispersion of the calculated rates using the prediction interval $(\mathrm{PI})$ and $\mathrm{I}^{2}$ percentage values. The $\mathrm{PI}$ gives an idea of the range of the dispersion and $\mathrm{I}^{2}$ tell us what proportion of the dispersion is true vs chance [9]. The calculated PIs are reported with the pooled rates in $>$ Table 1 . The calculated PI was narrow for the calculated pooled rates of clinical success, with minimal $I^{2}$ heterogeneity. This means the reported values are decently close to the expected values in the real world.

\section{Publication bias}

Based on visual inspection of the funnel plot as well as quantitative measurement that used the Egger regression test, there was no evidence of publication bias (Supplementary Fig.17, Eggers 2-tailed $P=0.15$ ). 




- Fig. 2 Forest plot, 12-m clinical success, POEM and PD.

\section{Discussion}

The results of this meta-analysis show that POEM performed significantly better than PD, in terms of clinical success for the treatment of achalasia. We report a statistically significant pooled odds ratio (OR) of clinical success with POEM at 12and 24-month follow-up, as compared to PD.

With a total of 6268 patients from 29 POEM cohorts and 33 PD cohorts, this is the most updated and the largest meta-analysis on the clinical outcomes of POEM and the first comparison meta-analysis to PD in the treatment of achalasia. Based on our study, we report a pooled OR of 8.97 and 5.64 in the rate of clinical success with POEM in the treatment of achalasia compared to PD, at 12- and 24-month follow-up, respectively.

In addition, the pooled proportions of clinical success at 12 , 24, and 36 months with POEM were superior to those of PD. The apparent superior clinical success of POEM over PD could potentially be due to incomplete disruption of the circular muscle of the esophagus during PD, whereas during POEM the esophageal circular muscle and potentially the longitudinal muscle are disrupted. Moreover, POEM is a technique that is witnessing rapid improvements in the learning curve that will have a favorable effect on the clinical success, adverse events and post-POEM reflux.

Our study also shows that the clinical efficacy of both POEM and PD tends to decrease with time, as shown bey the pooled clinical success rates at 12 months for POEM vs PD $(92.9 \%$ vs $76.9 \%)$, at 24 months for POEM vs PD (90.9\% vs $74.8 \%$ ), and at 36 months for POEM vs PD (88.4\% vs $72.2 \%)$. This highlights the underlying degenerative process of ganglion cells in achalasia with currently no treatment options to restore normal esophageal function. Accordingly, patients will require longterm follow-up and may need repeated or alternative treatments. Nevertheless, the clinical results of PD decreased during follow-up as compared with POEM, demonstrating a better intermediate and long-term efficacy of POEM over PD.

In this present study, POEM demonstrated superior results versus PD for achalasia subtypes I, II, and III (92.7\% vs $61 \%$; $96.6 \%$ vs $80.3 \%$; and $92.3 \%$ vs $41.9 \%$, respectively). Though these data were based on non-comparative analysis, this metaanalysis demonstrates the value of POEM for each achalasia subtype especially for type III (spastic) achalasia, for which outcomes of other treatments have been suboptimal. POEM allows for a longer myotomy that is generally not possible with pneu- 


\section{4-m clinical success, POEM \& PD}



- Fig. 3 Forest plot, 24-m clinical success, POEM and PD.

36-m clinical success, POEM \& PD

\begin{tabular}{lllll}
\multirow{2}{*}{$\begin{array}{l}\text { Group by } \\
\text { Intervention }\end{array}$} & Study name & \multicolumn{3}{c}{ Statistics for each study } \\
& & $\begin{array}{l}\text { Event } \\
\text { rate }\end{array}$ & $\begin{array}{l}\text { Lower } \\
\text { limit }\end{array}$ & $\begin{array}{l}\text { Upper } \\
\text { limit }\end{array}$ \\
\cline { 2 - 5 } & & 0.727 & 0.596 & 0.828 \\
PD & Tanaka et al 2010 & 0.579 & 0.419 & 0.724 \\
PD & Mikaeli et al 2004 Group A & 0.618 & 0.498 & 0.725 \\
PD & Mikaeli et al 2004 Group B & 0.618 \\
PD & Persson et al 2015 & 0.864 & 0.652 & 0.955 \\
PD & Dagli et al 2009 & 0.829 & 0.747 & 0.888 \\
PD & & 0.722 & 0.622 & 0.804 \\
POEM & Inoue et al 2015 & 0.885 & 0.778 & 0.944 \\
POEM & Guo et al 2017 & 0.881 & 0.779 & 0.939 \\
POEM & Nabi et al 2017 & 0.902 & 0.785 & 0.959 \\
POEM & Peng et al 2017 & 0.846 & 0.549 & 0.961 \\
POEM & & 0.884 & 0.805 & 0.933
\end{tabular}

Event rate and $95 \% \mathrm{Cl}$

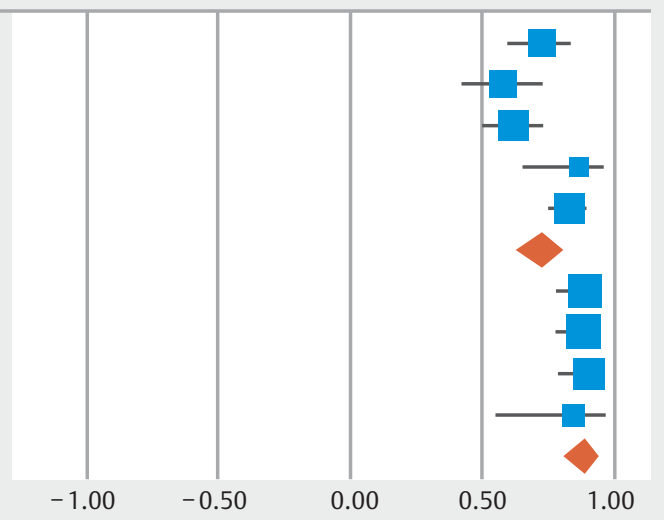

Fig. 4 Forest plot, 36-m clinical success, POEM and PD.

matic dilation, potentially contributing to its clear superior efficacy when compared to PD in patients with type III achalasia. Recent guidelines recommended POEM as the preferred treatment option for achalasia type III [93]

GERD is a well-established AE post POEM. Based on our analysis, the pooled OR of GERD by symptoms was 2.95 and the pooled rate of reflux esophagitis by EGD was 6.98, both were significantly higher with POEM as compared to PD $(P=0.02$ and $P=0.001$, respectively). Based on our analysis of cohort data, the pooled rate of post-POEM GERD, as reported by symptoms was $19 \%$, as diagnosed by reflux esophagitis on EGD was $27.5 \%$ and as diagnosed by $\mathrm{pH}$ monitoring was $48.6 \%$. The cor- 
responding values with $\mathrm{PD}$ were $17.8 \%, 14 \%$ and $41 \%$, respectively. It is important to note that not all patients underwent post procedure gastroscopy surveillance and $\mathrm{pH}$ monitoring. Only 89 patients $(3.3 \%$ ) of PD patients were subjected to surveillance gastroscopy and $\mathrm{pH}$ monitoring.

While the clinical implications of the increased acid exposure caused by POEM are currently incompletely understood, the high incidence of post-POEM pathologic reflux is of concern. Given this data, it is imperative that patients undergoing POEM are counseled regarding the increased risk of post-procedure reflux compared with pneumatic dilation. Post-procedure management options include objective testing for esophageal acid exposure, use of long-term acid suppressive therapy, and surveillance upper endoscopy should be considered. Emerging data suggest that combining POEM with anti-reflux measures, such as transoral incisional fundoplication (TIF), may decrease the incidence of esophagitis and lower the need for long-term proton pump inhibitor (PPI) use [94]. We were unable to assess POEM procedural factors such as anterior vs posterior myotomy, limiting the length of the gastric myotomy and preserving the collar sling muscle that are known to reduce the rates of post-POEM reflux, as it was out of scope for this study.

Our pooled results on the adverse events, as defined by the ASGE lexicon, were comparable between POEM and PD. Most intraprocedural adverse events (e.g., bleeding, mucosectomy, symptomatic pneumoperitoneum) can be addressed and treated endoscopically without any sequelae. Mild AEs POEM vs PD (2.8\% vs $2 \%, P=0.5)$ and moderate AEs POEM vs PD (3.1\% vs $2.3 \%, P=0.10)$ were comparable; similarly severe adverse events were noted in POEM vs PD ( $1.4 \%$ vs $1.8 \%(P=0.5)$, establishing the fact that POEM and PD are both highly safe procedures.

The strengths of this review are as follows: systematic literature search with well-defined inclusion criteria, careful exclusion of redundant studies, inclusion of high-quality studies with detailed extraction of data and rigorous evaluation of study quality. We report both OR and cohort-based subgroup comparison in our meta-analysis.

There are limitations to this study, most of which are inherent to any meta-analysis. The included studies were not entirely representative of the general population and community practice, with most studies being performed at tertiary-care referral centers. Our analysis had studies that were retrospective in nature contributing to selection bias and limited by few direct comparative trials. Variability in the definitions of reported outcomes among studies may have also affected the results. Especially with the use of variable definitions of dysphagia assessment and Eckhardt's score cut-off. PD protocol in PD studies were not uniform and we were not able to ascertain if a repeat dilation was allowed in all the PD studies included. Additionally, in assessing outcomes of PD, some studies considered some of the included patients as treatment failure based on single dilation, whereas conventionally clinical failure is determined after multiple graded dilations. Moreover, authors acknowledge that the reported OR are derived from non-RCT studies, and unrandomized, non-blinded selection of patients might have an influence on the reported outcomes.

\section{Conclusions}

In conclusion, based on our meta-analysis, POEM demonstrates significantly better clinical success when compared to PD at 12 , 24 and 36-month follow-up. Both procedures appear safe and the rate of severe adverse events are low. GERD seemed to occurs significantly more often after POEM in comparative data, however the rates were comparable in cohort studied. Future well-conducted studies to establish our findings and study the long-term data on its consequences, surveillance and management are needed.

\section{Competing interests}

Dr. Thosani is a consultant for Boston Scientific, Medtronic, Endogastric Solutions, and Pentax of America; a speaker for Abbvie, and receives royalties from UpToDate. Dr. Khashab is a consultant for Boston Scientific, Medtronic and Olympus. Dr. Repici receives consulting fees, speaker fees, and research grants from Boston Scientific; is an advisory board speaker for Fujifilm; receives an advisory board consulting fee from ERBE; is on the EndoKey advisory board; is on the EndoStart advisory board; and is on the advisory board for and receives research grants and consulting fees from Medtronic. Dr. Wani is a Consultant for Boston Scientific, Medtronic, Cernostics, and Interpace. This work was supported by the University of Colorado Department of Medicine Outstanding Early Scholars Program.

\section{References}

[1] Vaezi MF, Pandolfino JE, Vela MF. ACG clinical guideline: diagnosis and management of achalasia. Am J Gastroenterol 2013; 108: 1238-1249 quiz 50

[2] Fisichella PM, Raz D, Palazzo F et al. Clinical, radiological, and manometric profile in 145 patients with untreated achalasia. World J Surg 2008; 32: 1974-1979

[3] Sadowski DC, Ackah F, jiang B et al. Achalasia: incidence, prevalence and survival. A population-based study. Neurogastroenterol Motil 2010; 22: e256-e261

[4] Boeckxstaens GE, Zaninotto G, Richter JE. Achalasia. Lancet 2014; 383: 83-93

[5] Cheng JW, Li Y, Xing WQ et al. Laparoscopic Heller myotomy is not superior to pneumatic dilation in the management of primary achalasia: Conclusions of a systematic review and meta-analysis of randomized controlled trials. Medicine (Baltimore) 2017; 96: e5525

[6] Inoue H, Minami H, Kobayashi Y et al. Peroral endoscopic myotomy (POEM) for esophageal achalasia. Endoscopy 2010; 42: 265-271

[7] Stavropoulos SN, Desilets DJ, Fuchs KH et al. Per-oral endoscopic myotomy white paper summary. Gastrointest Endosc 2014; 80: 1-15

[8] Moher D, Liberati A, Tetzlaff J et al. Preferred Reporting Items for Systematic Reviews and Meta-Analyses: The PRISMA Statement. Ann Int Med 2009; 151: 264-269

[9] Stroup DF, Berlin JA, Morton SC et al. Meta-analysis of observational studies in epidemiology: a proposal for reporting. Meta-analysis Of Observational Studies in Epidemiology (MOOSE) group. JAMA 2000; 283: 2008-2012

[10] Stang A. Critical evaluation of the Newcastle-Ottawa scale for the assessment of the quality of nonrandomized studies in meta-analyses. Eur J Epidemiol 2010; 25: 603-605 
[11] Cotton PB, Eisen GM, Aabakken L et al. A lexicon for endoscopic adverse events: report of an ASGE workshop. Gastrointest Endosc 2010; 71: 446-454

[12] Glenny AM, Altman DG, Song F et al. Indirect comparisons of competing interventions. Health Technol Assess 2005; 9: 1-134

[13] DerSimonian R, Laird N. Meta-analysis in clinical trials. Control Clin Trials 1986; 7: 177-188

[14] Sutton AJ, Jones DR et al. Methods for Meta-Analysis in Medical Research. Wiley; 2000: 348

[15] Higgins JP, Thompson SG, Spiegelhalter DJ. A re-evaluation of random-effects meta-analysis. J R Stat Soc Ser A Stat Soc 2009; 172: 137-159

[16] Riley RD, Higgins JP, Deeks JJ. Interpretation of random effects metaanalyses. BMJ 2011: 342-549

[17] Mohan BP, Adler DG. Heterogeneity in systematic review and metaanalysis: how to read between the numbers. Gastrointest Endosc 2019; 89: 902-903

[18] Kanwal F, White D. "Systematic Reviews and Meta-analyses" in Clinical Gastroenterology and Hepatology. Clin Gastroenterol Hepatol 2012; 10: 1184-1186

[19] Higgins JP, Thompson SG, Deeks J] et al. Measuring inconsistency in meta-analyses. BMJ 2003; 327: 557-560

[20] Guyatt GH, Oxman AD, Kunz R et al. GRADE guidelines: 7. Rating the quality of evidence-inconsistency. | Clin Epidemiol 2011; 64: 12941302

[21] Easterbrook PJ, Berlin JA, Gopalan R et al. Publication bias in clinical research. Lancet 1991; 337: 867-872

[22] Duval S, Tweedie R. Trim and fill: A simple funnel-plot-based method of testing and adjusting for publication bias in meta-analysis. Biometrics 2000; 56: 455-463

[23] Borenstein M. Publication Bias in Meta-Analysis: Prevention, Assessment and Adjustments.Rothstein HR. Wiley; 2005: 376

[24] de Pascale S, Repici A, Puccetti F et al. Peroral endoscopic myotomy versus surgical myotomy for primary achalasia: single-center, retrospective analysis of 74 patients. Dis Esophagus 2017; 30: 1-7

[25] Gulati S, Emmanuel A, Inoue $\mathrm{H}$ et al. Peroral endoscopic myotomy: a literature review and the first UK case series. Clin Med (Lond) 2017; 17: $22-28$

[26] Guo H, Yang H, Zhang X et al. Long-term outcomes of peroral endoscopic myotomy for patients with achalasia: a retrospective singlecenter study. Dis Esophagus 2017; 30: 1-6

[27] Hungness ES, Sternbach JM, Teitelbaum EN et al. Per-oral endoscopic myotomy (POEM) after the learning curve: durable long-term results with a low complication rate. Ann Surg 2016; 264: 508-517

[28] Inoue $\mathrm{H}$, Sato $\mathrm{H}$, Ikeda $\mathrm{H}$ et al. Per-oral endoscopic myotomy: a series of 500 patients. J Am Coll Surg 2015; 221: 256-264

[29] Kumagai K, Tsai JA, Thorell A et al. Per-oral endoscopic myotomy for achalasia. Are results comparable to laparoscopic Heller myotomy? Scand J Gastroenterol 2015; 50: 505-512

[30] Louie BE, Schneider AM, Schembre DB et al. Impact of prior interventions on outcomes during per oral endoscopic myotomy. Surg Endosc 2017; 31: 1841-1848

[31] Lv L, Liu J, Tan Y et al. Peroral endoscopic full-thickness myotomy for the treatment of sigmoid-type achalasia: outcomes with a minimum follow-up of 12 months. Eur J Gastroenterol Hepatol 2016; 28: 30-36

[32] Meng F, Li P, Wang Y et al. Peroral endoscopic myotomy compared with pneumatic dilation for newly diagnosed achalasia. Surg Endosc 2017; 31: 4665-4672

[33] Patel KS, Calixte R, Modayil RJ et al. The light at the end of the tunnel: a single-operator learning curve analysis for per oral endoscopic myotomy. Gastrointest Endosc 2015; 81: 1181-1187
[34] Peng L, Tian S, Du C et al. Outcome of peroral endoscopic myotomy (POEM) for treating achalasia compared with laparoscopic heller myotomy (LHM). Surg Laparosc Endosc Percutan Tech 2017; 27: 6064

[35] Ponds FA, Fockens P, Lei A et al. Effect of peroral endoscopic myotomy vs pneumatic dilation on symptom severity and treatment outcomes among treatment-naive patients with achalasia: a randomized clinical trial. JAMA 2019; 322: 134-144

[36] Wang X, Tan Y, Lv L et al. Peroral endoscopic myotomy versus pneumatic dilation for achalasia in patients aged $\geq 65$ years. Rev Esp Enferm Dig 2016; 108: 637-641

[37] Ward MA, Gitelis M, Patel L et al. Outcomes in patients with over 1 -year follow-up after peroral endoscopic myotomy (POEM). Surg Endosc 2017; 31: 1550-1557

[38] Zheng Z, Zhao C, Su S et al. Peroral endoscopic myotomy versus pneumatic dilation - result from a retrospective study with 1 -year follow-up. Z Gastroenterol 2019; 57: 304-311

[39] Ramchandani M, Nageshwar Reddy D, Darisetty S et al. Peroral endoscopic myotomy for achalasia cardia: Treatment analysis and follow up of over 200 consecutive patients at a single center. Dig Endosc 2016; $28: 19-26$

[40] Ngamruengphong S, Inoue H, Ujiki MB et al. Efficacy and safety of peroral endoscopic myotomy for treatment of achalasia after failed Heller myotomy. Clin Gastroenterol Hepatol 2017; 15: 1531-1537

[41] Sharata AM, Dunst CM, Pescarus R et al. Peroral endoscopic myotomy (POEM) for esophageal primary motility disorders: analysis of 100 consecutive patients. J Gastrointest Surg 2015; 19: 161-170 discussion 70

[42] Duan T, Tan Y, Zhou J et al. A retrospective study of peroral endoscopic full-thickness myotomy in patients with severe achalasia. J Laparoendosc Adv Surg Tech A 2017; 27: 770-776

[43] Tang X, Gong W, Deng Z et al. Feasibility and safety of peroral endoscopic myotomy for achalasia after failed endoscopic interventions. Dis Esophagus 2017; 30: 1-6

[44] Tang X, Ren Y, Gao Q et al. Peroral endoscopic myotomy is safe and effective in achalasia patients aged older than 60 years compared with younger patients. Geriatr Gerontol Int 2017; 17: 2407-2413

[45] Zhang X, Modayil RJ, Friedel D et al. Per-oral endoscopic myotomy in patients with or without prior Heller's myotomy: comparing longterm outcomes in a large U.S. single-center cohort (with videos). Gastrointest Endosc 2018; 87: 972-985

[46] Alderliesten J, Conchillo JM, Leeuwenburgh I et al. Predictors for outcome of failure of balloon dilatation in patients with achalasia. Gut 2011; 60: 10-16

[47] Aljebreen AM, Samarkandi S, Al-Harbi T et al. Efficacy of pneumatic dilatation in Saudi achalasia patients. Saudi J Gastroenterol 2014; 20 43-47

[48] Andreevski V, Nojkov B, Krstevski M et al. Short and medium-term therapeutic effects of pneumatic dilatation for achalasia: a 15-year tertiary centre experience. Pril (Makedon Akad Nauk Umet Odd Med Nauki) 2013; 34: 15-22

[49] Borges AA, Lemme EM, Abrahao LJ et al. Pneumatic dilation versus laparoscopic Heller myotomy for the treatment of achalasia: variables related to a good response. Dis Esophagus 2014; 27: 18-23

[50] Bravi I, Nicita MT, Duca P et al. A pneumatic dilation strategy in achalasia: prospective outcome and effects on oesophageal motor function in the long term. Aliment Pharmacol Ther 2010; 31: 658-665

[51] Chen X, Li QP, Ji GZ et al. Two-year follow-up for 45 patients with achalasia who underwent peroral endoscopic myotomy. Eur J Cardiothorac Surg 2015; 47: 890-896

[52] Chuah SK, Hu TH, Wu KL et al. Clinical remission in endoscope-guided pneumatic dilation for the treatment of esophageal achalasia: 7-year 
follow-up results of a prospective investigation. J Gastrointest Surg 2009; 13: 862-867

[53] Dagli U, Kuran S, Savas N et al. Factors predicting outcome of balloon dilatation in achalasia. Dig Dis Sci 2009; 54: 1237-1242

[54] Dobrucali A, Erzin Y, Tuncer M et al. Long-term results of graded pneumatic dilatation under endoscopic guidance in patients with primary esophageal achalasia. World J Gastroenterol 2004; 10: 33223327

[55] Doder R, Perisic N, Tomasevic R et al. Long-term outcome of a modified balloon dilatation in the treatment of patients with achalasia. Vojnosanit Pregl 2013; 70: 915-922

[56] Elliott TR, Wu PI, Fuentealba S et al. Long-term outcome following pneumatic dilatation as initial therapy for idiopathic achalasia: an 18-year single-centre experience. Aliment Pharmacol Ther 2013; 37 : $1210-1219$

[57] Ghoshal UC, Rangan M, Misra A. Pneumatic dilation for achalasia cardia: reduction in lower esophageal sphincter pressure in assessing response and factors associated with recurrence during long-term follow up. Dig Endosc 2012; 24: 7-15

[58] Hamdy E, El Nakeeb A, El Hanfy E et al. Comparative study between laparoscopic heller myotomy versus pneumatic dilatation for treatment of early achalasia: a prospective randomized study. J Laparoendosc Adv Surg Tech A 2015; 25: 460-464

[59] Hassan MK, Khattak MA, Bakhtiar S et al. Long term results of single session of pneumatic dilatation with $30 \mathrm{MM}$ balloon for achalasia cardia. J Postgrad Med Instit (Peshawar-Pakistan) 2017: 31

[60] Howard JM, Mongan AM, Manning B] et al. Outcomes in achalasia from a surgical unit where pneumatic dilatation is first-line therapy. Dis Esophagus 2010; 23: 465-472

[61] Hulselmans M, Vanuytsel T, Degreef T et al. Long-term outcome of pneumatic dilation in the treatment of achalasia. Clin Gastroenterol Hepatol 2010; 8: 30-35

[62] Karamanolis G, Sgouros S, Karatzias G et al. Long-term outcome of pneumatic dilation in the treatment of achalasia. Am J Gastroenterol 2005; 100: 270-274

[63] Khashab MA, Kumbhari V, Tieu AH et al. Peroral endoscopic myotomy achieves similar clinical response but incurs lesser charges compared to robotic heller myotomy. Saudi J Gastroenterol 2017; 23: 91

[64] Li SW, Tseng PH, Chen CC et al. Muscular thickness of lower esophageal sphincter and therapeutic outcomes in achalasia: A prospective study using high-frequency endoscopic ultrasound. J Gastroenterol Hepatol 2018; 33: 240-248

[65] Ling TS, Guo HM, Yang T et al. Effectiveness of peroral endoscopic myotomy in the treatment of achalasia: a pilot trial in Chinese Han population with a minimum of one-year follow-up. J Dig Dis 2014; 15 : 352-358

[66] Maris T, Kapetanos D, Ilias A et al. Mid term results of pneumatic balIoon dilatation in patients with achalasia. Ann Gastroenterol 2010: 61-63

[67] Mikaeli J, Bishehsari F, Montazeri G et al. Injection of botulinum toxin before pneumatic dilatation in achalasia treatment: a randomizedcontrolled trial. Aliment Pharmacol Ther 2006; 24: 983-989

[68] Moonen A, Annese V, Belmans A et al. Long-term results of the European achalasia trial: a multicentre randomised controlled trial comparing pneumatic dilation versus laparoscopic Heller myotomy. Gut 2016; 65: 732-739

[69] Novais PA, Lemme EM. 24-h pH monitoring patterns and clinical response after achalasia treatment with pneumatic dilation or laparoscopic Heller myotomy. Aliment Pharmacol Ther 2010; 32: 12571265

[70] Park JH, Lee YC, Lee $\mathrm{H}$ et al. Residual lower esophageal sphincter pressure as a prognostic factor in the pneumatic balloon treatment of achalasia. J Gastroenterol Hepatol 2015; 30: 59-63
[71] Persson J, Johnsson E, Kostic S et al. Treatment of achalasia with laparoscopic myotomy or pneumatic dilatation: long-term results of a prospective, randomized study. World J Surg 2015; 39: 713-720

[72] Sabharwal T, Cowling M, Dussek J et al. Balloon dilation for achalasia of the cardia: experience in 76 patients. Radiology 2002; 224: 719724

[73] Schneider AM, Louie BE, Warren HF et al. A matched comparison of per oral endoscopic myotomy to laparoscopic Heller myotomy in the treatment of achalasia. J Gastrointest Surg 2016; 20: 1789-1796

[74] Shejal AH, Ramachandran TM, Kumar S. Clinical outcome of pneumatic dilatation in patients with achalasia cardia: A single-center prospective study. J Digest Endosc 2017; 8: 182-186

[75] Spiliopoulos S, Sabharwal T, Inchingolo R et al. Fluoroscopically guided balloon dilatation for the treatment of achalasia: long-term outcomes. Dis Esophagus 2013; 26: 213-218

[76] Tanaka Y, Iwakiri K, Kawami $\mathrm{N}$ et al. Predictors of a better outcome of pneumatic dilatation in patients with primary achalasia. J Gastroenterol 2010; 45: 153-158

[77] Teitelbaum EN, Soper NJ, Santos BF et al. Symptomatic and physiologic outcomes one year after peroral esophageal myotomy (POEM) for treatment of achalasia. Surg Endosc 2014; 28: 3359-3365

[78] von Renteln D, Fuchs KH, Fockens P et al. Peroral endoscopic myotomy for the treatment of achalasia: an international prospective multicenter study. Gastroenterology 2013; 145: 309-11.e1-3

[79] Werner YB, von Renteln D, Noder T et al. Early adverse events of peroral endoscopic myotomy. Gastrointest Endosc 2017; 85: 708-18.e2

[80] Worrell SG, Alicuben ET, Boys J et al. Peroral endoscopic myotomy for achalasia in a thoracic surgical practice. Ann Thorac Surg 2016; 101: 218-24; discussion 24-25

[81] Yamashita H, Ashida K, Fukuchi T et al. Predictive factors associated with the success of pneumatic dilatation in Japanese patients with primary achalasia: a study using high-resolution manometry. Digestion 2013; 87: 23-28

[82] Zerbib F, Thetiot V, Richy F et al. Repeated pneumatic dilations as long-term maintenance therapy for esophageal achalasia. Am J Gastroenterol 2006; 101: 692-697

[83] Kim WH, Cho JY, Ko WJ et al. Comparison of the outcomes of peroral endoscopic myotomy for achalasia according to manometric subtype. Gut Liver 2017; 11: 642-647

[84] Lee JY, Kim N, Kim SE et al. Clinical characteristics and treatment outcomes of 3 subtypes of achalasia according to the Chicago classification in a tertiary institute in Korea. J Neurogastroenterol Motil 2013; 19: 485-494

[85] Martinek J, Svecova H, Vackova Z et al. Per-oral endoscopic myotomy (POEM): mid-term efficacy and safety. Surg Endosc 2018; 32: 12931302

[86] Muller M, Keck C, Eckardt AJ et al. Outcomes of pneumatic dilation in achalasia: Extended follow-up of more than 25 years with a focus on manometric subtypes. J Gastroenterol Hepatol 2018; 33: 1067-1074

[87] Nabi Z, Ramchandani M, Chavan R et al. Peroral endoscopic myotomy in treatment-naive achalasia patients versus prior treatment failure cases. Endoscopy 2018; 50: 358-370

[88] Pandolfino JE, Kwiatek MA, Nealis T et al. Achalasia: a new clinically relevant classification by high-resolution manometry. Gastroenterology 2008; 135: 1526-1533

[89] Rohof WO, Salvador R, Annese V et al. Outcomes of treatment for achalasia depend on manometric subtype. Gastroenterology 2013; 144: 718-725 quiz e13-4

[90] Ghoshal UC, Rangan M. A review of factors predicting outcome of pneumatic dilation in patients with achalasia cardia. J Neurogastroenterol Motil 2011; 17: 9-13

[91] Zhang WG, Linghu EQ, Chai NL et al. Ling classification describes endoscopic progressive process of achalasia and successful peroral 
endoscopy myotomy prevents endoscopic progression of achalasia. World J Gastroenterol 2017; 23: 3309-3314

[92] Kim WH, Cho JY, Ko WJ et al. Comparison of the outcomes of peroral endoscopic myotomy for achalasia according to manometric subtype. Gut Liver 2017; 11: 642-647

[93] Kahrilas PJ, Katzka D, Richter JE. Clinical practice update: the use of per-oral endoscopic myotomy in achalasia: expert review and best practice advice from the AGA Institute. Gastroenterology 2017; 153 : 1205-1211

[94] Tyberg A, Choi A, Gaidhane M et al. Transoral Incisionless fundoplication for reflux after peroral endoscopic myotomy: a crucial addition to our arsenal. Endosc Int Open 2018; 6: E549-E552 